We welcome letters to the Editor concerning articles which have recently been published. Such letters will be subject to the usual stages of selection and editing; where appropriate the authors of the original article will be offered the opportunity to reply.

Letters should normally be under $\mathbf{3 0 0}$ words in length, doublespaced throughout, signed by all authors and fully referenced. The edited version will be returned for approval before publication.

(C)2007 British Editorial Society of Bone and Joint Surgery \$2.00 J Bone Joint Surg [Br] 2007;89-B:846-7.

\section{Acute shortening and re-lengthening in the management of bone and soft-tissue loss in complicated fractures of the tibia}

Sir,

I read with interest the paper by El-Rosasy ${ }^{1}$ in the January 2007 issue entitled "Acute shortening and re-lengthening in the management of bone and soft-tissue loss in complicated fractures of the tibia." The author managed 21 patients with a fracture/nonunion of the tibia complicated by bone and softtissue loss by the acute shortening and re-lengthening method. The author concluded that acute shortening and re-lengthening is another powerful technique for bridging soft tissue and bone defects and restoration of limb function in one procedure without the need for further reconstructive procedures in most cases. In addition, this method could be recommended for use as definitive treatment immediately after trauma, but could not be considered as a salvage procedure, to ensure the best functional results.

We reported six patients with type IIIB open tibial fractures treated with primary shortening and limb lengthening, ${ }^{2}$ similar to acute shortening and re-lengthening by the author. The mean shortening length was $7.4 \mathrm{~cm} \mathrm{(4.5} \mathrm{to} 10)$. The mean percentage shortening of the entire bone was $18.7 \%(12.3 \%$ to $29.7 \%$ ). Limb lengthening started at a mean interval of 10.3 months (3 to 18 ) after the original injury. Regarding functional outcome (by Puno et $\mathrm{al}^{3}$ ), three patients showed good results, two fair, and one poor. The percentage shortening of the bone in the two fair cases was more than $25 \%$. The median physical health, mental health, and total general health subscales of the SF36 (quality of living) ${ }^{4}$ were lower than the standard scales for age-matched individuals. Our primary shortening and limb lengthening treatment was also thought to be a useful option for severe open fractures of the tibia, with a bony defect of more than $4.5 \mathrm{~cm}$ in length after serial debridement. However, it is difficult to achieve an excellent function and quality of living using these techniques, based on our results. In addition, it is difficult for patients who underwent limb lengthening after a shortening of more than $25 \%$ of the total length of bone to gain good function.
We agree with the author's method for severe complicated fracture of the tibia. However, we consider that the author should report the functional outcome, such as the SF36. Moreover, shortening should be evaluated as a percentage of the total length of bone.

doi:10.1302/0301-620X.89B8.19833

K. YOKOYAMA, MD, PhD, Director of Orthopaedic Surgery

Machida Municipal Hospital, Machida, Tokyo, Japan.

1. El-Rosasy MA. Acute shortening and re-lengthening in the management of bone and soft-tissue loss in complicated fractures of the tibia. J Bone Joint Surg $[\mathrm{Br}]$ 2007;89-B:80-8

2. Yokoyama K, Itoman $\mathbf{M}$, Nakamura K, et al. Primary shortening with secondary limb lengthening for Gustilo IIIB open tibial fractures: a report of six cases. J Trauma 2006;61:172-80.

3. Puno RM, Grossfeld SL, Henry SL, et al. Functional outcome of patients with salvageable limbs with grades III-B and III-C open fractures of the tibia. Microsurgery 1996;17:167-73.

4. Ware JE Jr, Sherbourne CD. The MOS 36-item short-form health survey (SF-36). I: Conceptual framework and item selection. Med Care 1992;30:473-83.

\section{Author's reply:}

Sir,

I thank Dr Yokoyama for his interest in my paper. This study was conducted with two main goals: first, to make a clearer definition of the relatively safe limits for acute limb shortening so that immediate fracture stability could be obtained and to avoid difficulties frequently encountered with bone transport; and secondly, to present a more refined technique for acute limb shortening with emphasis on the approaches used in order to achieve the safest possible outcome. The basic concept behind this and any other technique is not to do harm and to achieve the best possible functional outcome. ${ }^{1}$

Dr Yokoyama et $\mathrm{al}^{2}$ reported the results of their treatment for six cases of grade III open tibial fractures using primary shortening and secondary limb lengthening. It may be an attractive idea to estimate the amount of limb shortening as a percentage of the entire bone length in a manner similar to isolated limb lengthening. However, it would be impossible to draw solid conclusions based on the results of case reports. On the other hand, we believe that the amount of the safe acute limb shortening should not be estimated in this way for several reasons. When undertaking acute limb shortening, the soft tissues have to buckle to close the defect, causing a kinked neurovascular bundle and possible acute ischaemia. In the proximal third of the leg, muscle bulk and anatomical tethering of the vessels hinder shortening compared to that undertaken in the middle and lower thirds of the leg. For this we have estimated the amount of shortening based on the level of the defect. However, each case has to be evaluated on its merit due to the interaction of several factors: the patient's age 
(younger patients with healthy vessels can tolerate more shortening), the presence of chronic infection and soft-tissue induration hinder acute limb shortening and for a single artery limb, acute shortening should be practised with great caution. Heroic attempts at closure of wide defects by acute shortening, in excess of the estimated safe limits, should be avoided. For such defects it may be wiser to undertake partial shortening and subsequent gradual compression or bone transport, preferably trifocal compression-distraction if applicable. An alternative approach is to acutely shorten the limb to narrow the defect and then manage the remaining defect using vascularised soft-tissue flaps. ${ }^{3}$

In their report, Dr Yokoyama et $\mathrm{al}^{2}$ stated that limb lengthening was started between 3 and 18 months after injury. A delay of this length results in adaptive soft-tissue contracture and renders subsequent limb lengthening much more difficult with frequent complications. The nature of their complications resides in the application of the technique and not in the technique itself; this particular group of cases most probably represents their early experience with this technique. This can be perceived from the unacceptably high complications in their reported six cases (one infected corticotomy, one deep infection at the shortening site, one refracture at the docking site, several wire breakages in two cases, and two severe equinovarus deformities) and the modest functional outcome (no excellent, three good, two fair and one poor). Despite these results they find their technique a useful option for the treatment of severe open fractures of the tibia with a bony defect of more than $4.5 \mathrm{~cm}$ after debridement. Reconstruction of the limb using external fixation is reserved for the complicated cases in most centres. For many of these cases belowknee amputation was suggested, and the patient chose to keep his leg and undergo reconstruction. From a functional standpoint, a below-knee prosthesis would allow better function than a stiff foot and ankle. However, we do not recommend amputation and find the achievement of bony union and leg length equalisation so formidable a task that both the surgeon and the patient will accept a less than optimal functional outcome. It would be unrealistic to base the evaluation of results solely on the functional outcome. The functional outcome of post-traumatic limb reconstruction is mainly predetermined by the soft-tissue status, so an excellent bone result does not guarantee a similarly excellent functional outcome. ${ }^{4}$ There is a lack of a universally accepted and validated scoring system for post-traumatic limb reconstruction based on both bone and functional evaluations. A larger study, possibly a multi-centre study, is needed to develop such a validated scoring system, with more specific inclusion criteria and evaluation parameters, for which we have been working for several years in our institution.

doi:10.1302/0301-620X.89B8.19834

M. A. EL-ROSASY, MSc, MD, Lecturer of Orthopaedic Surgery

Faculty of Medicine, University of Tanta, Tanta, Egypt.

1. Sen C, Kocaoglu M, Eralp L, Gulsen M, Cinar M. Bifocal compression-distraction in the acute treatment of grade III open tibia fractures with bone and soft-tissue loss: a report of 24 cases. J Orthop Trauma 2004;18:150-7.

2. Yokoyama $\mathbf{K}$, Itoman $\mathbf{M}$, Nakamura $\mathbf{K}$, et al. Primary shortening with secondary limb lengthening for Gustilo IIIB open tibial fractures: a report of six cases. J Trauma 2006;61:172-80

3. Watson JT, Anders M, Moed BR. Management strategies for bone loss in tibial shaft fractures. Clin Orthop 1995;315:138-52.

4. Paley D, Catagni MA, Argnani F, et al. llizarov treatment of tibial nonunions with bone loss. Clin Orthop 1989;241:146-65. 